\title{
Maxillo-facial Trauma: Epidemiological Study and Legal Implications
}

\author{
Sami Bardaa ${ }^{1,2}$, Hanen Dhouib ${ }^{1,2, ~}$, Hassen Ennouri ${ }^{1,2}$, Zouhir Hammami ${ }^{1,2}$, Samir Maatoug ${ }^{1,2}$ \\ ${ }^{1}$ Forensic Department, Habib Bourguiba University Hospital, Sfax, Tunisia \\ ${ }^{2}$ Medicine Faculty, University of Sfax, Sfax, Tunisia
}

\section{Email address:}

bardaasami@yahoo.fr (S. Bardaa), dhouibhanen@yahoo.fr (H. Dhouib), hassenennouri@gmail.com (H. Ennouri), zouhir.hammami@rns.tn (Z. Hammami),samirmaatoug@yahoo.com (S. Maatoug)

${ }^{*}$ Corresponding author

\section{To cite this article:}

Sami Bardaa, Hanen Dhouib, Hassen Ennouri, Zouhir Hammami, Samir Maatoug. Maxillo-facial Trauma: Epidemiological Study and Legal Implications. International Journal of Clinical Oral and Maxillofacial Surgery. Vol. 6, No. 1, 2020, pp. 1-6.

doi: 10.11648/j.ijcoms.20200601.11

Received: January 18, 2020; Accepted: February 13, 2020; Published: February 28, 2020

\begin{abstract}
In Tunisia, as all over the world, intentional traumas resulting from assaults represent a growing social scourge especially after the revolution of January 2011. Facial trauma occupies a special place due to its psychological impact on victims. This study aims to examine the demographics, pattern and management of maxillofacial injuries due to interpersonal violence. It's about a retrospective study, interesting all cases of isolated intentional maxillofacial traumas collected in the Forensic Department of the University Hospital Habib Bourguiba of Sfax - Tunisia during six months between July and December 2017. We collected 270 cases of isolated facial trauma with a prevalence of $7.3 \%$. Victims were mainly young men with low socio-economic class. Bruise was the most frequent lesion $(67.4 \%)$. Orbital region was the most common site of lesions (52.2\%). Total temporary disability (TTD) average was 10.81 days. Permanent partial disability (PPD) was predicted in $34.8 \%$ of cases. Despite the low prevalence of isolated facial trauma, it is considered as a major public health problem. Consequences of the complaint lodged by the victim depend on conclusions of medicolegal expertise.
\end{abstract}

Keywords: Interpersonal Assault, Maxillofacial Trauma, Forensic Medical Report

\section{Introduction}

In Tunisia, as all over the world, intentional traumas resulting from assaults is a growing social scourge especially after the revolution of January 2011. Particular attention is given to maxillofacial traumas because of the importance of the human face. On the first hand, it often constitutes the first point of contact in various human interactions and is frequently the preferred target for blows in assault cases. On the second hand, psychological disabilities resulting from esthetic damage are far away deep than injuries somewhere else on the human body. Thus, maxillofacial traumas are considered as a major public health problem due to their effects as well as their legal and judicial implications.

This study aims to examine the demographics, pattern and management of maxillofacial injuries due to interpersonal violence. Such data also assist with raising awareness of the legal implications of these injuries.

\section{Materials and Methods}

We carried out a descriptive and analytical retrospective study over a period of 6 months from 1 July 2017 to 31 December 2017. Characteristics of assaults and injuries were collected from the forensic medical report delivered by forensic doctors during the consultation at the Forensic Department of the University Hospital Habib Bourguiba of Sfax - Tunisia. After a physical examination of the victim, the following elements were taken into account: type of weapon used to inflict the injury, wound characteristics, gravity of injuries, total temporary disability (TTD) and prediction of permanent partial disability (PPD).

We included all cases of isolated maxillofacial trauma resulting from an assault. We didn't include maxillofacial trauma associated with other types of injuries or resulting 
from road traffic accident or following a sexual assault.

Data collection:

Data were compiled and analyzed using SPSS software version $20.0 \AA$ for Windows ${ }^{\circledR}$.

Statistical analysis:

Descriptive study:

Quantitative variables were described using means, standard deviation and limits.

Qualitative variables were described using proportions.

Analytical study:

Study of the associations between the variables was made by the hypothesis tests. Comparison of proportions was performed by the Pearson "chi-square" test or by the "Fisher" exact test for the independent samples.

Mann Whitney test was used to compare the averages of two independent samples. The receiver-operator characteristic (ROC) curve has been drawn up. Area under the curve (AUC) was measured by a non-parametric method.

A" $p$ " value less than 0.05 was considered statistically significant

\section{Results}

Among 3671 patients seen in our consultation unit for intentional assault and battery, 2181 (59.4\%) cases involved assaults, 270 had isolated maxillofacial trauma, with a prevalence of $7.3 \%$. The average age of patients was 31 years (range 1 to 84 years). 21 to 30 and 31 to 40 age groups accounted respectively $30.4 \%$ and $27.4 \%$. There was male preponderance (sex ratio $=3.6$ ). Day laborers were the most affected socio-professional category, with 133 cases (49.3\%). The weapon used was a natural blunt object in 212 cases (78.5\%). (table 1)

Assaults were more frequent over the weekend with a rate of $16.3 \%$ on Saturdays and $18.5 \%$ on Sundays. Delay between assault and medical report was short. In fact, $43.3 \%$ of victims consult the same day of the aggression and $50 \%$ within 7 days. (table 1)

Among soft tissues injuries, bruises were the most prevalent in 182 cases $(67.4 \%)$. The most common site of injury was the orbital region in 141 cases (52.2\%). (table 2)

Wounds accounted for $27.8 \%$ of cases ( 75 cases). 52 open wounds required suture and medical treatment. (table 2)

Among the 32 patients with maxillofacial skeletal fractures, nasal bones (10.74\%) were the most prevalent site of injury in our study. Four patients had mandibular fractures and 3 had zygomatic arches fractures. (table 2)

Ten patients $(3.7 \%)$ underwent surgery. Only 6 patients $(2.2 \%)$ required prolonged hospitalization. (table 2 )

Total temporary disability (TTD) ranged from 0 to 45 days (Median $=10$ days). It was significantly correlated with the presence of a fracture, an open wound, or dental trauma, whether it was mobility, tooth loss, or alveolar fracture of one tooth or more. (table 3 )

Permanent partial disability (PPD) was predicted in 94 patients $(34.8 \%)$. The occurrence of a PPD also depended on certain lesions such as fractures, open wounds and dental lesions. (table 4)

Using Mann Whitney test, we noticed a significant correlation between TTD and PPD ( $\mathrm{U}=560, \mathrm{p}<0.001)$. According to the results of the ROC curve (see Figure 1), a TTD around 10 days represents the threshold at which a PPI is expected. (figure 1)

\section{Discussion}

\subsection{Epidemiology of Intentional Isolated Maxillofacial Trauma}

Violence is a major problem worldwide. Cultural and social characteristics may result in varying injury patterns between victims in different nations and communities [1]. After the revolution of January 2011, Tunisia experienced many socio-demographic changes. In fact, judicial complaints following assaults and battery have been steadily increasing [2]. Maxillofacial injuries represent a particular aspect of all injuries resulting from interpersonal violence. They constituted $7.3 \%$ of our consultations in Forensic Department of the University Hospital Habib Bourguiba of Sfax - Tunisia. This rate remains higher than the one found in a study conducted by Diallo et al. In Conakry [3] as well as that described by Kaïta et al in 2013 [4].

Laski and al [5] reported that the majority (75\%) of maxillofacial injuries are due to violence. In addition to that, according to Boffano et al [6. 7], aggression was the most common mechanism of maxillofacial trauma in $39 \%$ of cases. However, assaults are not the only mechanism causing isolated maxillofacial injuries. In fact, many other studies reported that assaults ranked after road traffic accident [8].

\subsection{Characteristics of Maxillofacial Injuries}

Maxillofacial injuries affected mostly male patients (sexratio $=3.6$ ). This ratio was within the ranges described in the literature [10-13]. 21 to 30 and 31 to 40 age groups accounted more than the half of cases $(57.7 \%)$. This agrees with other studies [10]. In fact, this age group corresponds to the period of full vitality in men in which there is an increase of risky behaviors.

According to our study, the greatest incidence of maxillofacial trauma was observed in lower socioeconomic group. Indeed, the day laborers as well as the unemployed constituted the social class most affected. Several studies have investigated the factors that contribute to maxillofacial trauma (MFT), such as the Al Dajani study [14], which showed that the majority of patients hospitalized for maxillofacial injuries were from underprivileged backgrounds. Kebina's study [15] showed that 90\% of patients with maxillofacial injuries were from the suburbs of Dakar and according to Olasoji'study [16], the increase in the rate of maxillofacial fractures resulting from assaults may be associated with the high youth-unemployment's rate following the Nigerian economic collapse (thesis).

In addition, we noticed that maxillofacial injuries occurred more often on Sundays followed by Saturdays. The incidence 
of maxillofacial trauma on other days of the week was much lesser. A similar increase in assault-related maxillofacial injuries on weekends has been reported by other studies [1719]. This can be explained by the increase in alcohol consumption in the weekend. Indeed, some studies include the consumption of alcohol and drugs such as marijuana, cocaine and heroin in these traumas regardless of the etiology $[20,21]$ by the depression of the inhibitory mechanisms of the brain, this association can go as far as in $55 \%$ of cases. [22]. Unfortunately, this notion is not studied in our paper because the forensic medical reports do not specify whether there is an alcohol or drug consumption at the relevant time.

\subsection{Injury Types}

Clinically, the bruise was the most reported injury according to forensic medical reports $(67.4 \%)$. This is conflicting with findings reported by Diallo AO et al. [16]. They reported that wounds were the most frequent injury $(66.9 \%)$ and bruises represent only $14.4 \%$ among injuries found. The anatomic distribution of maxillofacial fractures is widely variable. Many authors reported the mandible as the most frequently affected site [13], whereas others reported this to be the zygomatico-maxillary complex [17, 22]. However, in our study, nasal bones were the most prevalent site of fractures which corroborates with an Indian finding [7]. In fact, the foreground position of nasal bones in the facial skeleton $[23,24]$ would explain the high frequency of this impairment in our study.

\subsection{Severity of Injuries}

Although serious injuries have a greater socioeconomic impact, their legal implications are more serious. Its severity depends as much on the nature of the injuries as on the weapon used. In fact, the resulting total temporary disability (TTD) is longer and it is more likely to give rise to a permanent partial disability (PPD). From a legal perspective, PPD is decisive in the legal qualification of the offense committed.

\subsection{Total Temporary Disability (TTD)}

Total Temporary Disability (TTD) is defined as the period during which an injured person, victim of assault or battery, will be unable. It is the inability or the limitation in carrying out daily life's defined tasks and activities (toilet, clothing, eating, travel, etc.) $[25,26]$. Even a housewife or a child can benefit from TTD. This period is therefore not synonymous of the work stoppage which may be different from the legal TTD. In fact, an employee with a sprained ankle requiring immobilization by plastered boot can go to work with two canes crutches.

However, the jurisprudence tends to accept the existence of a certain physical ability of the victim; otherwise the only total incapacity would be coma state or death! [26]. Moreover, when a victim is hospitalized, the period of hospitalization is the minimum length of the TTD.

Estimating the TTD is difficult because it must take into account the objective injuries (location, nature and severity of lesions), their functional impact and the length of care required. Currently, there is no objective scale of disability assessment available to physicians who are required to prepare forensic medical reports. [27]

In our study, TTD ranged from 0 days to 45 days for patients with multiple fractures of the face or mandible or zygomatic arch. The TTD was significantly correlated with the presence of a fracture, an open wound, or dental trauma, whether it was mobility, tooth loss, or alveolar fracture of one tooth or more. This can be explained by the fact that these lesions are more severe and require a longer period for recovery.

Unfortunately, no other studies discussed the TTD due to maxillofacial injuries in the literature review.

\subsection{Permanent Partial Disability (PPD)}

Permanent partial disability (PPD) is defined as the definitive impairment of the victim after consolidation, expressed in relation to functional capacity just before the occurrence of the causal event [28]. The disability assessment is generally expressed as a percentage that indicates the extent to which the injury limits motion, sensory perceptions, or physiological function. It can be expected initially at the injury stage, by the time of the medical report writing. However, it is determined, at the stage of sequelae, during the forensic medical expertise requested by the competent judicial authority. In our region, the PPD is the most important indicator of an assault's severity [28]. It helps to guide the legal classification of the offense committed. The initial expertise of the violence's victims is, then, capital for the qualification of the assault of "serious". However, this standard has been considerably criticized since the PPD cannot be determined with rigor until after long enough period necessary for the consolidation, which delays the legal proceedings.

In our series, a PPD was predicted at the end of the initial examination in $65.5 \%$ of cases. According to our results, PPD depends mainly on the presence of bone fracture, open wound or dental lesions (fractures, avulsions and tooth mobility). We noticed a significant correlation between TTD and PPD ( $U=560, p<0.001$, Mann Whitney). According to the results of the ROC curve (see Figure 1), a TTD around 10 days represents the threshold at which a PPD is expected.

\subsection{Legal Implications of Assault and Battery with Maxillofacial Injuries}

The initial medical report prepared by the medical examiner is crucial for the legal qualification of the offense.

In fact, the, a priori, slight violence where initial lesions will evolve without leaving any traces is directed by the prosecutor to the competent cantonal court. They are judged on the basis of Article 319 of the Tunisian Penal Code (TPC) which provides: "are punishable by 15 days in prison and four dinars eight hundred thousand cents, the perpetrators of brawls and those who engage in assault or violence causing 
no other serious or lasting consequence for the health of others..." [29].

On the other hand, if there is a PPD expected, the case will be judged in the court of first instance:

- In a correctional room if the PPD's rate expected is less than twenty percent. In this case, Article 218 of the TPC will be applied, which states that: "Anyone who voluntarily injures, beats, or commits any other violence or assault not falling within predictions of Article 319, is punishable by one year's imprisonment and a fine of 1,000 dinars (1000d) " [30].

Article 219 "When the above-mentioned violence has been followed by mutilation, loss of use of a limb, disfigurement, infirmity or permanent incapacity whose rate does not exceed $20 \%$, the guilty party shall be punished by five years of imprisonment

In criminal chamber, after investigation, if the PPD's rate expected is higher than twenty percent. In this case, Article 219 of the TPC will be applied. It states that: ".... The sentence will be ten years in prison, if the result of these kinds of violence is a disability whose rate exceeds $20 \%$ "[28]. Violence is considered criminal from the outset.

In addition, the nature of the weapon used may have more serious legal implications. Indeed, bearing sharp weapon or using it can be source of offense and additional punishment. Article 218 of the CPT provides that mutilation or disfigurement is punishable "if there has been premeditation of three years' imprisonment and three thousand dinars (3000d) fine". [29]. The same is true for firearms, it is the law $n \circ 69-33$ of June 12th, 1969 which stipulates that "the carrying of the weapons... is forbidden as well as their transport without legitimate motive... punished of a imprisonment of two to five years and a fine of three hundred to three thousand dinars ". [30]

When there is a kinship relationship between the victim and the perpetrator such as cases of ascendants or descendants, penalties are more serious. Article 219 of the CPT provides that "the penalty shall be increased to twelve years' imprisonment if the offender is a descendant of the victim, regardless of the rate of incapacity, even in the event of withdrawal". [29]

\section{Conclusion}

Maxillofacial trauma is common during our consultation at the Forensic Department of Sfax. They mainly concern young men with low socio-economic class. Bruise is the most frequent lesion. Fractures indicate a serious trauma expecting PPD and longer TTD. The initial medical certificate is primordial in these types of assaults. Indeed, doctors should be aware of the consequences of this certificate for the victim and the abuser. On one hand, the victim may receive illicit and unjustified benefits and allowances. On the other hand, abusive interpretations by the doctor can make offender serve unjust punishment.

\section{Appendix}

Table 1. Description of study's population.

\begin{tabular}{lll}
\hline & Headcount & Percentage \\
\hline Age range & 11 & \\
$0-10$ & 39 & $4,1 \%$ \\
$11-20$ & 82 & $14,4 \%$ \\
$21-30$ & 74 & $30,4 \%$ \\
$31-40$ & 41 & $27,4 \%$ \\
$41-50$ & 17 & $15,2 \%$ \\
$51-60$ & 6 & $6,3 \%$ \\
$>61$ & & $2,2 \%$ \\
Gender & 212 & \\
Male & 58 & $78,5 \%$ \\
Female & & $21,5 \%$ \\
Origin & 157 & \\
Urban & 113 & $58,1 \%$ \\
Rural & & $41,9 \%$ \\
Profession & 68 & \\
None & 133 & $25,2 \%$ \\
Day laborer & 9 & $49,3 \%$ \\
Senior manager & 12 & $3,3 \%$ \\
Student & 14 & $4,4 \%$ \\
Officer & 31 & $5,2 \%$ \\
Liberal occupation & 3 & $11,5 \%$ \\
Retiree & & $1,1 \%$ \\
\hline
\end{tabular}

Table 2. Characteristics of aggression.

\begin{tabular}{|c|c|c|}
\hline & Headcount & Percentage \\
\hline \multicolumn{3}{|l|}{ Time of consultation } \\
\hline$<24$ hours & 117 & $43,3 \%$ \\
\hline 1-7 days & 135 & $50 \%$ \\
\hline $7-15$ days & 10 & $3,7 \%$ \\
\hline $15-30$ days & 6 & $2,2 \%$ \\
\hline$>1$ month & 2 & $0,7 \%$ \\
\hline \multicolumn{3}{|l|}{ Weapon used } \\
\hline Natural weapons & 212 & $78,5 \%$ \\
\hline Blunt object & 191 & $29,3 \%$ \\
\hline Edged weapon & 11 & $4,1 \%$ \\
\hline \multicolumn{3}{|l|}{ Type of lesions } \\
\hline Abrasion & 142 & $52,6 \%$ \\
\hline Bruise & 182 & $67,4 \%$ \\
\hline Contused wound & 64 & $23,7 \%$ \\
\hline Linear wound & 11 & $4,1 \%$ \\
\hline Hematoma & 13 & $4,8 \%$ \\
\hline Loss of tissue & 2 & $0,7 \%$ \\
\hline Teeth mobility & 14 & $5,2 \%$ \\
\hline Teeth fracture & 18 & $6,7 \%$ \\
\hline Teeth fall & 9 & $3,3 \%$ \\
\hline Bone Fracture & 29 & $10,8 \%$ \\
\hline Subconjunctival hemorrhage & 44 & $16,3 \%$ \\
\hline Corneal lesion & 8 & $3 \%$ \\
\hline \multicolumn{3}{|l|}{ Site of lesions } \\
\hline Orbit & 141 & $52,5 \%$ \\
\hline Forehead & 86 & $31,9 \%$ \\
\hline Zygomatic arch & 33 & $12,2 \%$ \\
\hline Nose & 86 & $31,6 \%$ \\
\hline Mouth & 89 & $33 \%$ \\
\hline Cheek & 51 & $18,9 \%$ \\
\hline Peri oral & 17 & $6,3 \%$ \\
\hline Chin & 9 & $3,3 \%$ \\
\hline Mandible & 10 & $3,7 \%$ \\
\hline \multicolumn{3}{|l|}{ Injury care } \\
\hline Suture & 52 & $19,3 \%$ \\
\hline Hospitalization & 6 & $2,2 \%$ \\
\hline Surgery & 10 & $3,7 \%$ \\
\hline Prevision of permanent partial di & & \\
\hline
\end{tabular}




\begin{tabular}{lll}
\hline & Headcount & Percentage \\
\hline Yes & 94 & $65,2 \%$ \\
No & 176 & $34,8 \%$ \\
\hline
\end{tabular}

Table 3. Variation of total temporary disability depending of nature of injuries.

\begin{tabular}{ll}
\hline Injury & $\mathbf{P}$ \\
\hline Abrasion & 0,682 \\
Bruise & 0,47 \\
Contused wound & 0,000 \\
Linear wound & 0,003 \\
Fracture & 0,000 \\
Teeth mobility & 0,034 \\
Teeth fall & 0,002 \\
Teeth fracture & 0,000 \\
\hline
\end{tabular}

Table 4. Risk factors that may predict the occurrence of permanent partial disability.

\begin{tabular}{ll}
\hline Injury & P \\
\hline Contused wound & 0,001 \\
Linear wound & 0,000 \\
Fracture & 0,000 \\
Teeth mobility & 0,001 \\
Teeth fall & 0,001 \\
Teeth fracture & 0,000 \\
\hline
\end{tabular}

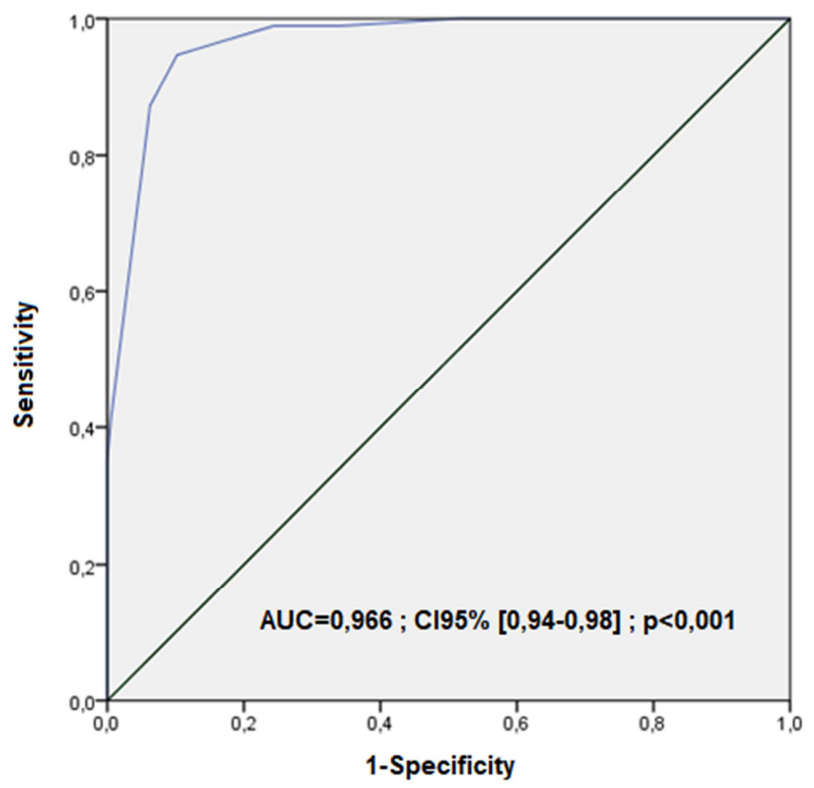

Figure 1. ROC Curve Correlation between total temporary disability and prevision of permanent partial disability.

\section{Declaration of Interest}

There is no conflict of interest affecting any author.

\section{References}

[1] Brink O, Vester A, Jensen J. Pattern of injuries due to interpersonal violence. Injury 1998; 29: 705-709.

[2] [2] Nouma. Y et al. "L'incapacité totale temporaire: évaluation et conséquences médicolégales". Journal International De Victimologie. 2012, 2-2014.
[3] Diallo, Alpha Oumar, FA Itiere Odzili, A Keita, ML Bah, HM Alloh, A Kourouma, B Conde, SAT Camara, AV Sylla, \& G Ondzotto. "Traumatismes Isolés de la Face à Conakry: Considérations Épidémiologiques et Prise en Charge." HEALTH SCIENCES AND DISEASES [Online], 18.4 (2017): n. pag. Web. 9 Sep. 2018.

[4] Keïta A, Diallo AO, Condé M, Fofana M, Barry AO, Diallo MT, Camara S. Les urgences ORL au CHU de Conakry. Guinée Méd. 2013; 81: 19-26.

[5] Laski R, Ziccardi VB, Broder HL, Janal M. Facial trauma: a recurrent disease? The potential role of disease prevention. J Oral Maxillofac Surg 2004; 62: 685-688.

[6] Boffano, Paolo et al. "European Maxillofacial Trauma (EURMAT) project: a multicentre and prospective study." Journal of cranio-maxillo-facial surgery: official publication of the European Association for Cranio-Maxillo-Facial Surgery 431 (2015): 62-70.

[7] HWANG, Kun et YOU, Sun Hye. Analysis of facial bone fractures: An 11-year study of 2,094 patients. Indian journal of plastic surgery: Official publication of the Association of Plastic surgeons of India, 2010, vol. 43, no 1, p. 42.

[8] Gadre, K. S., Halli, R., Joshi, S., Ramanojam, S., Gadre, P. K., Kunchur, R.,... \& Kaul, D. (2013). Incidence and pattern of cranio-maxillofacial injuries: a 22 year retrospective analysis of cases operated at major trauma hospitals/centres in Pune, India. Journal of maxillofacial and oral surgery, 12 (4), 372378 .

[9] Gassner, R., Tuli, T., Hächl, O., Rudisch, A., \& Ulmer, H. (2003). Cranio-maxillofacial trauma: a 10 year review of 9543 cases with 21067 injuries. Journal of cranio-maxillofacial surgery, 31 (1), 51-61.

[10] Lee KH, Snape L, Steenberg LJ, Worthington J. Comparasion between interpersonal violence and motor vehicle accidents in the aetiology of maxillofacial fractures. ANZ J Surg. 2007; 77: 695-8.

[11] Rajendra PB, Mathew TP, Agrawal A, Sabharawal G. Characteristics of associated craniofacial with head injuries: An experience with 100 cases. J Emerg Trauma Shock. 2009; 2: 89-94.

[12] Zargar M, Khaji A, Karbakhsh M, Zarei MR. Epidemiology study of facial injuries during a 13 month of trauma registry in Tehran. Indian J Med Sci. 2004; 58: 109-14.

[13] Lee KH. La violence interpersonnelle et des fractures du visage. J Oral Maxillofac Surg. 2009; 67: 1878-1883.

[14] Al-Dajani, M., et al. Epidemiology of maxillofacial injuries in Ontario, Canada. J Oral Maxillofac Surg, 2015. 73 (4): p. 693 e1-9.

[15] Kebina, B. K. les traumatismes maxillo-faciaux: étude rétrospective de 1255 cas colligés au chu ARISTIDE LE DANTEC DE DAKAR de janvier 2004 à décembre 2006. 2008, UNIVERSITE CHEIKH ANTA DIOP DE DAKAR.

[16] Olasoji H. O., Tahir A., Arotiba G. T. Changing picture of facial fractures in northern Nigeria. (2002) British Journal of Oral and Maxillofacial Surgery, 40 (2), pp. 140-143.

[17] Kapoor, Pranav, and Namita Kalra. "A retrospective analysis of maxillofacial injuries in patients reporting to a tertiary care hospital in East Delhi." International journal of critical illness and injury science 2.1 (2012): 6. 
[18] Lee, Kai. "Global trends in maxillofacial fractures." Craniomaxillofacial trauma \& reconstruction 5.4 (2012): 213.

[19] Subhashraj, K., N. Nandakumar, and C. Ravindran. "Review of maxillofacial injuries in Chennai, India: a study of 2748 cases." British Journal of Oral and Maxillofacial Surgery 45.8 (2007): 637-639.

[20] Lee, Jung Hoon, Byung Ki Cho, and Woo Jin Park. "A 4-year retrospective study of facial fractures on Jeju, Korea." Journal of Cranio-Maxillofacial Surgery 38.3 (2010): 192-196.

[21] Hutchison, I. L., et al. "The BAOMS United Kingdom survey of facial injuries part 1: aetiology and the association with alcohol consumption." British Journal of Oral and Maxillofacial Surgery 36.1 (1998): 3-13.

[22] Ogundare, Bolaji O., Andrea Bonnick, and Neil Bayley. "Pattern of mandibular fractures in an urban major trauma center." Journal of Oral and Maxillofacial Surgery 61.6 (2003): 713-718.

[23] Mabrouk, Amr, et al. "Incidence, etiology, and patterns of maxillofacial fractures in Ain-Shams University, Cairo, Egypt: A 4-year retrospective study." Craniomaxillofacial trauma \& reconstruction 7.3 (2014): 224.
[24] Eggensperger, Nicole, et al. "A 3-year survey of assaultrelated maxillofacial fractures in central Switzerland." Journal of Cranio-Maxillofacial Surgery 35.3 (2007): 161-167.

[25] J. Pouillard: Les certificats médicaux. UNAFORMEC. 2005. pp 2-4.

[26] G. Lorin de la Grandmaison, Michel Durigon. Incapacité totale de travail: proposition d'un barème indicatif. LA REVUE DU PRATICIEN-MÉDECINE GÉNÉRALE. TOME 20. Janvier 2006. pp. 71 8-7 19.

[27] P. Chariot, F. Dedouit, C. R-Salmon, N. Bourokba, C. RMaillart, G. Tournel. Examen médical des personnes victimes de violence: fréquence des facteurs aggravants au sens du Code pénal, hétérogénéité des pratiques. La Presse Médicale, Volume 41, Issue 11, November 2012, pp e553-e558.

[28] E. Baccino. Médecine de la violence: prise en charge des victimes et des agresseurs. Chapitre 4: victimes des violences physiques (aspects pénaux), pp 76-139.

[29] Code pénal tunisien (CPT).

[30] Base de données: la législation du secteur de la sécurité en Tunisie. Loi $\mathrm{n}^{\circ}$ 69-33 du 12 juin 1969, réglementant l'introduction, le commerce, la détention et le port des armes. 